\title{
Kinetic studies on thermal degradation of natural rubber/butyl rubber
}

\author{
Muhammad Sholeh*, Ihda Novia Indrajati, Arum Yuniari \\ Center for Leather, Rubber, and Plastics, Jl. Sokonandi No. 9 Yogyakarta 55166, Indonesia \\ *Corresponding author. Tel.:+62 274 512929, 563939; Fax.:+62 274563655 \\ E-mail: muhammad-sholeh@kemenperin.go.id
}

Received: 31 October 2017 Revised: 15 May 2018 Accepted: 17 May 2018

\begin{abstract}
The knowledge of how rubber breakdown on heating in oxidative environment is important in processing and using the material. In this work, thermogravimetric analysis were carried out and three iso-conversional kinetic models were utilized to get apparent activation energies of thermal degradation of natural rubber (NR)/butyl rubber (IIR). Blending of NR/IIR and additives was conducted using a laboratory two-roll mill. Thermal degradation of the blends and its kinetic parameters were analysed using thermo gravimetric analysis (TGA) with heating rates of $5,10,15$, and $20^{\circ} \mathrm{C} / \mathrm{min}$. The kinetic parameters were determined by three isoconversional models (Kissinger, Doyle, and Flynn-Wall-Ozawa (FWO) model). The result revealed that the thermal decomposition of the blend occurs in two stages and the derivative thermogravimetric (DTG) peaks tends to shift to a higher temperature during TGA measurement. The values of DTG peaks increases with an increase of the heating rate, and the three iso-conversional models gave similar apparent activation energies. The activation energy obtained can be used to predict thermal lifetime of the material.
\end{abstract}

Keywords: Butyl rubber, Natural rubber, Thermal degradation, Kinetic studies.

\section{INTRODUCTION}

Rubber oxidation rate depends on many factor, such as rubber type, processing methods and service condition of the product. Oxidation stability determines the service life of the product because exposure of rubber to oxygen can result deterioration in its mechanical properties. The knowledge of how rubber breakdown on heating in oxidative environment is important. Production temperature is limited by the temperature at which the material starts to breakdown (Nabil et al., 2013).

Thermogravimetric analysis is one of the most widely accepted methods for determining the thermal properties of polymeric materials (Martins et al., 2008). It provides approximation of effective kinetic parameters for decomposition reactions of various materials (Wang \& Zhao, 2015). Zhao et al. (2013) analyzed the degradation kinetics of phenol-formaldehyde resins derived from beetle infested pine barks by using Kissinger and Kissinger-Akahira-Sunose methods. Zheng et al. (2015) used the isoconversional Flynn-Wall-Ozawa (FWO) method to calculate the kinetic paramesters of degradation of natural rubber (NR). Nabil et al. (2013) applied the Coats--Redfern's method to study thermal analysis of carbon black-filled NR/Virgin EPDM and NR/Recycled EPDM rubber blends.

To the best of our knowledge, no studies have focused on kinetic studies on thermal degradation of NR/IIR blend. The purpose of this study is to contrast the kinetic parameters generated by Kissinger, Doyle, and FWO model. We performed thermogravimetric analysis and utilized the three iso-conversional kinetic models to get apparent activation energies of thermal degradation of NR/IIR.

\section{MATERIALS AND METHODS Materials}

Natural rubber, ribbed smoked sheet (RSS) 1, was supplied by PTPN IX Indonesia. Butyl rubber 301 (Lanxess) with a density of 0.92 $\mathrm{mg} / \mathrm{m}^{3}$, an ash content of $0.8 \% \max$, and a mooney viscosity (ML $\left.+8 @ 125^{\circ} \mathrm{C}\right)$ of $50 \pm 5 \mathrm{MU}$ was obtained from Lanxess. Other compounding 
ingredients were carbon black (HAF black N 330 ex Black Cat), nano precipitated calcium carbonate (Diacal), paraffinic oil, tetramethyldihydroquinoline (TMQ) (Kemai), N-(1,3dimethylbutyl)-N'-phenyl-p-phenylendiamine (6PPD) (Starchem), zinc oxide ( $\mathrm{ZnO})$ ex Indoxide, aflux 42, paraffin wax (antilux 654 A), tetramethyl thiuram (TMT) (Bayer), mercapto benzothiazole (MBT) (Bayer), and sulphur ex Miwon.

\section{Methods \\ Compounding and vulcanization}

A conventional sulphur vulcanization system was employed with the following formulation: RSS $55 \mathrm{phr}$, butyl $45 \mathrm{phr}$, carbon black $50 \mathrm{phr}$, NPCC $5 \mathrm{phr}$, TMQ 2 phr, 6PPD 1 phr, wax $0.5 \mathrm{phr}$, ZnO $5 \mathrm{phr}$, aflux $421 \mathrm{phr}$, paraffinic oil $8 \mathrm{phr}$, TMT $0.5 \mathrm{phr}$, MBT $0.5 \mathrm{phr}$, and sulphur $2.5 \mathrm{phr}$. Blending of NR/IIR and additives was done according to previous study using a laboratory two-roll mill (Yuniari et al., 2015). Cure time of the blended compound was determined by a moving die rheometer (MDR) Gotech 3000A. The compound was compression moulded at $160^{\circ} \mathrm{C}$ with a pressure of $14.7 \mathrm{MPa}$ using a laboratory hot press.

\section{Thermogravimetric Analysis}

Thermogravimetric analysis was performed with a Perkin-Elmer Diamond Type TGA analyzer. The sample was scanned from $30^{\circ} \mathrm{C}$ to $800^{\circ} \mathrm{C}$ at air flow of $200 \mathrm{ml} / \mathrm{min}$ with a heating rate of $5,10,15$, and $20^{\circ} \mathrm{C} / \mathrm{min}$.

\section{RESULTS AND DISCUSSION \\ Thermogravimetric Analysis}

Thermogravimetric analysis measures weight changes of a sample as a function of temperature or time in a controlled atmosphere to determine the thermal, stabilities and compositional properties of the material (Nabil et al., 2013). The weight loss curve in Figure 1 shows the loss of mass of NR/IIR with temperature at different heating rates $5,10,15$, and $20^{\circ} \mathrm{C} / \mathrm{min}$ under air atmosphere. It shows the main mass loss stages move in the direction of higher temperature with the increase of heating rate. As can be seen from the plot, the decomposition process can be considered as a two-step reaction. The first step begins at about $200^{\circ} \mathrm{C}$ and proceeds rapidly with increasing temperature until about $400^{\circ} \mathrm{C}$. The second step proceeds until the final temperature of 560,615 , 613 , and $656^{\circ} \mathrm{C}$ for $5,10,15$, and $20^{\circ} \mathrm{C} / \mathrm{min}$

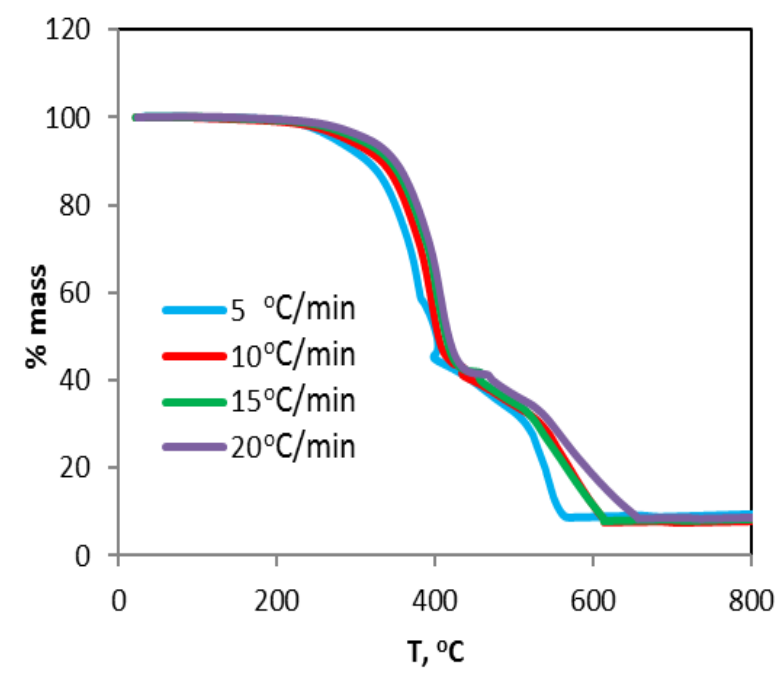

Figure 1. Weight loss curves of NR/IIR recorded in air at four heating rates.

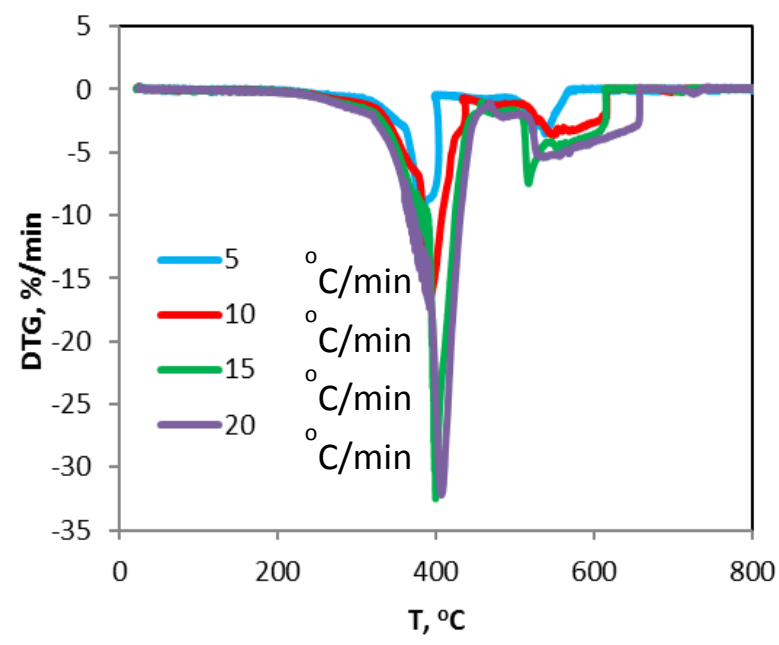

Figure 2. DTG curves of NR/IIR recorded in air at four heating rates.

respectively. The solid residue yields are about $8,6 \%$.

Figure 2 shows DTG curves of the sample. It can be seen that the DTG curves show two peaks, indicating that the thermo-oxidative degradation reaction in the air atmosphere can be considered as a two-step reaction. The first step is the decomposition of rubber chain and the second step is the further decomposition of aging products (Zheng et al., 2015). The values of DTG peaks increase with the increase of heating rate and DTG peaks tends to shift to a higher temperature (Table 1). This phenomenon most probably due to high heating rate increase thermal lag (Damartzis et al., 2011). 
Table 1. Temperature and values of DTG peaks, and solid residue yields at different heating rates.

\begin{tabular}{cccc}
\hline $\begin{array}{c}\text { Heating } \\
\text { rates, } \\
{ }^{\circ} \mathrm{C} / \mathrm{min}\end{array}$ & $\begin{array}{c}\mathrm{T}_{\max }, \\
{ }^{\circ} \mathrm{C}\end{array}$ & $\begin{array}{c}\mathrm{DTG}, \\
\% / \mathrm{min}\end{array}$ & $\begin{array}{c}\text { solid } \\
\text { residue } \\
\text { yields, \% }\end{array}$ \\
\hline 5 & 382.4 & -9.2 & 8.7 \\
10 & 392.3 & -16.5 & 7.5 \\
15 & 400.0 & -32.4 & 7.9 \\
20 & 407.1 & -32.2 & 8.4 \\
\hline
\end{tabular}

\section{Kinetic Analysis}

Combustion and pyrolysis of polymer can be assumed first order reaction. The rate of decomposition is demonstrated by the following equation (Xiang et al., 2014):

$$
\frac{\mathrm{d} \alpha}{\mathrm{d} t}=k(T) f(\alpha)
$$

Where $\alpha$ is mass loss fraction, $t$ is time during thermal degradation, and $k$ is rate constant. Mass loss fraction is defined as (Wang \& Zhao, 2015):

$$
\alpha=\frac{m_{\mathrm{i}}-m_{\mathrm{t}}}{m_{\mathrm{i}}-m_{\infty}}
$$

Where $m_{\mathrm{i}}$ is the initial mass sample, $m_{\mathrm{t}}$ is mass sample at $t$ time, and $m_{\infty}$ is the final mass. Rate constant is based on Arrhenius theory:

$$
k=A \exp \left(-\frac{E}{R T}\right)
$$

where $A$ is a pre-exponential factor, $E$ is activation energy, $R$ is universal gas constant, and $T$ is absolute temperature.

Combining Eqs (1) and (3), we get:

$$
\frac{\mathrm{d} \alpha}{\mathrm{d} t}=A \exp \left(-\frac{E}{R T}\right) f(\alpha)
$$

Introducing a constant heating rate $\beta=\mathrm{dT} / \mathrm{d} t$ and rearrangement gives the following equation:

$$
\frac{\mathrm{d} \alpha}{f(\alpha)}=\left(\frac{A}{\beta}\right) \exp \left(-\frac{E}{R T}\right) \mathrm{d} T
$$

Temperature integral of Eq. (5) has the following form:

$$
g(\alpha)=\left(\frac{A}{\beta}\right)_{0}^{T} \int_{0} \exp \left(-\frac{E}{R T}\right) \mathrm{d} T
$$

Where $g(\alpha)$ is the integration function. Because Eq. (6) does not have an analytic solution, many iso-conversional methods have been used to estimate the kinetic parameters.

Iso-conversional methods is simple and have been widely used to study reaction kinetics of combustion and pyrolysis of polymeric materials. Three iso-conversional methods are used in this work to find $E$ (Wang \& Zhao, 2015):

Kissinger:

$$
\ln \left(\frac{\beta}{T_{\alpha}^{2}}\right)=\ln \left(\frac{A R}{E_{\alpha} g(\alpha)}\right)-\frac{E_{\alpha}}{R T_{\alpha}}
$$

Doyle:

$$
\ln \beta=\ln \left(\frac{A E_{\alpha}}{\operatorname{Rg}(\alpha)}\right)-5.331-1.052 \frac{E_{\alpha}}{R T_{\alpha}}
$$

Flynn-Wall-Ozawa

$\log \beta=\log \left(\frac{A E_{\alpha}}{\operatorname{Rg}(\alpha)}\right)-2.315-0.457 \frac{E_{\alpha}}{R T_{\alpha}}$ (9)

Where $E_{\alpha}$ and $T_{\alpha}$ are apparent activation energy and temperature when $\alpha$ is a designed value. Activation energy can be obtained by plotting $\ln \left(\beta / T_{\alpha}^{2}\right)$ versus $-1 /\left(R T_{\alpha}\right)$, ln $\beta$ versus $1.052 /\left(R T_{\alpha}\right)$, and $\log \beta$ versus $-0.457 /\left(R T_{\alpha}\right)$ in Eq. (7), (8), and (9) respectively.

Figure 3 shows the change of the mass loss fraction with temperature of NR/IIR samples during combustion at different heating rate. The kinetic parameters were determined from the same value of mass loss fraction from 0.1 to 0.9 for all curves at different heating rate. Kissinger, Doyle and FWO model were plotted and presented in Figure 4. Apparent activation energy is obtained from the the slope of the line.

From Figure 4, it is evident that the predicted data from the three models are agreeable with the experimental data having $\mathrm{R}^{2}$ of $0.9361,0.9442$, and 0.9441 for Kissinger, Doyle, and FWO respectively. 


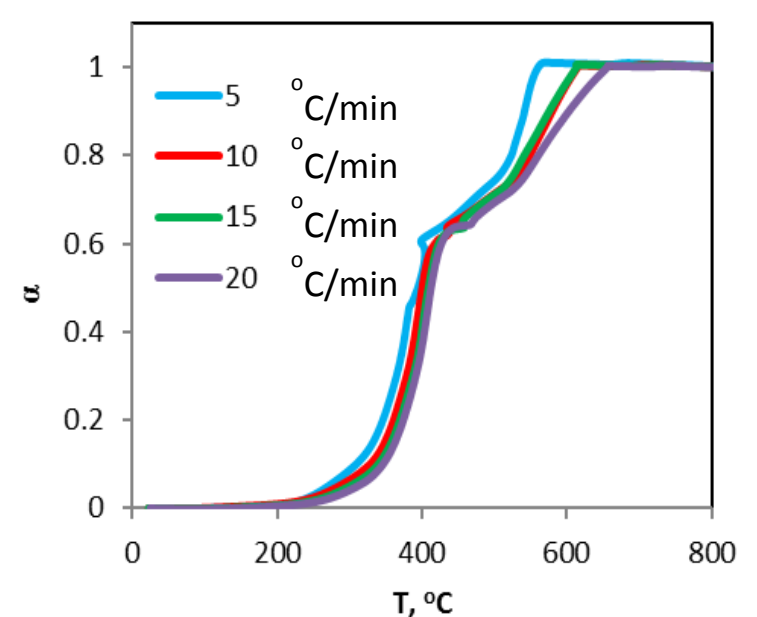

Figure 3. Mass loss fraction curve during combustion of NR/IIR.

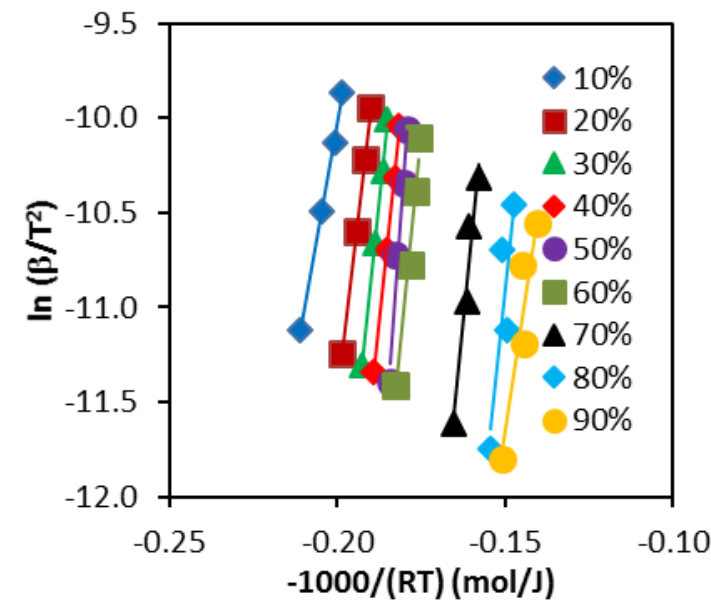

(a)
Figure 5 shows that the three isoconversional models give similar apparent activation energies. The difference of the $E_{\alpha}$ obtained by the three models is below $7.35 \mathrm{~kJ} / \mathrm{mol}$. $E_{\alpha}$ increase with the increase of mass loss fraction up to 0.5 and thereafter decrease. Below fractional mass loss of 0.5 , the initiation of the rubber main chain was followed by the autocatalytic oxidation process of rubber. The highest $E_{\alpha}$ value at mass loss fraction of 0.5 corresponds to the the intensification of the thermal-oxidative degradation process (Zheng et al., 2016). The highest $E_{\alpha}$ obtained at $\alpha=0.5$ are $253.17 \mathrm{~kJ} / \mathrm{mol}, 251.11 \mathrm{~kJ} / \mathrm{mol}$, and $251.04 \mathrm{~kJ} / \mathrm{mol}$ for Kissinger, Doyle, and FWO model respectively. This apparent activation energy can be used to predict thermal lifetime of the material.

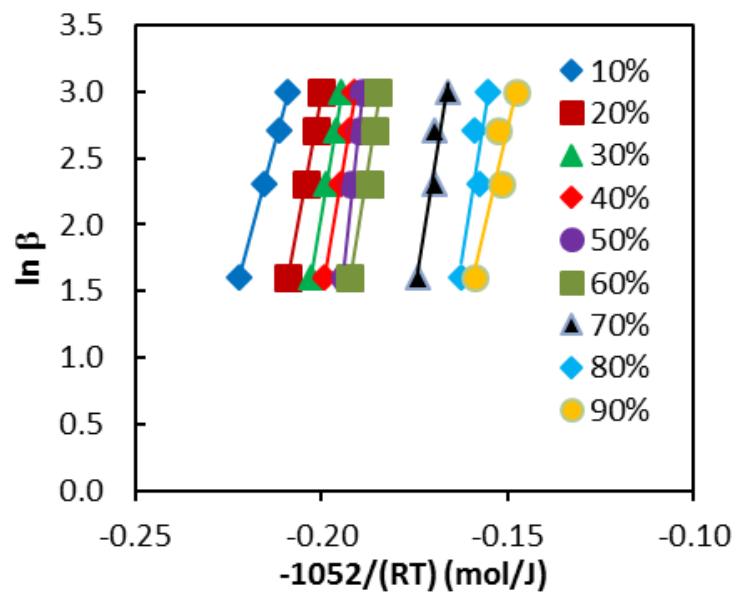

(b)

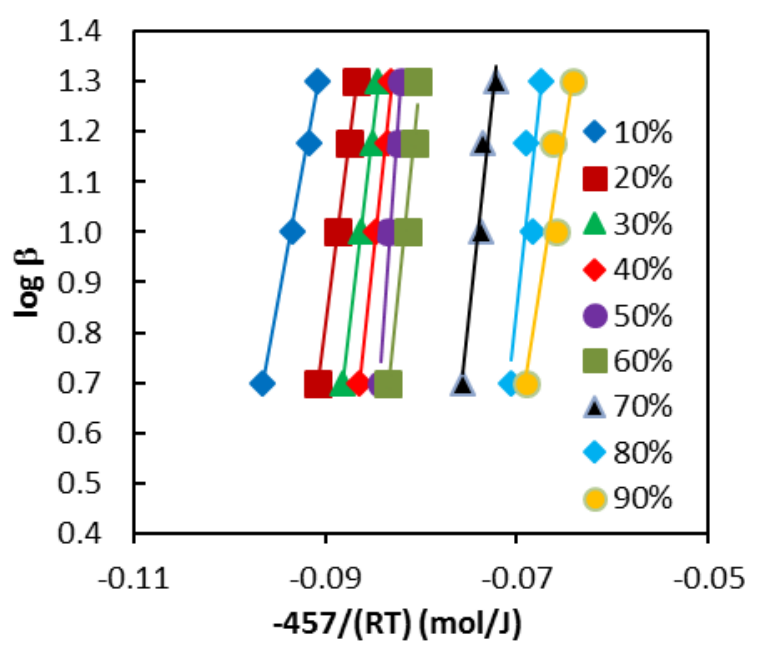

(c)

Figure 4. Plot of (a) Kissinger, (b) Doyle, and (c) FWO model. 


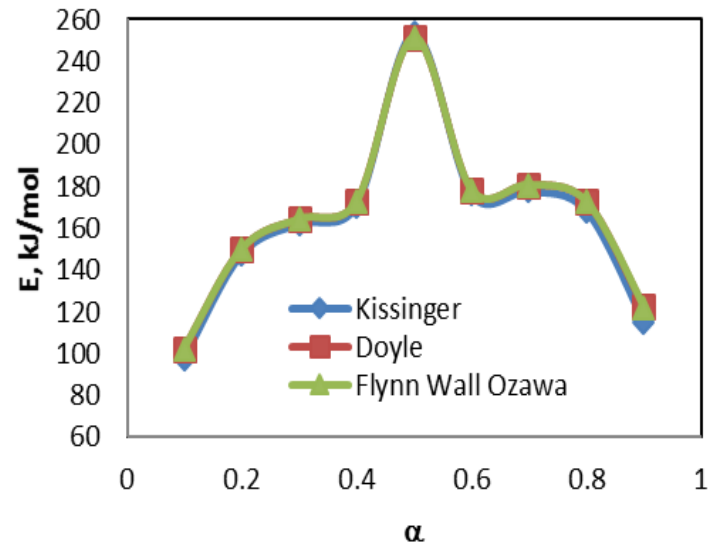

Figure 5. Plots of fractional mass loss $(\alpha)$ versus activation energy $\left(E_{\alpha}\right)$ determined by Kissinger, Doyle, and FWO model

\section{CONCLUSIONS}

An experimental kinetic study of thermal degradation of natural rubber/butyl rubber blend is presented where kinetic constants from three different models were determined and compared. Thermal decomposition of natural rubber/butyl rubber proceeds in two stage reaction. The results showed that values of kinetic parameters are in good agreement and that Kissinger, Doyle, and Flynn-Wall-Ozawa model satisfactorily described the degradation process. The difference of the $E_{\alpha}$ obtained by the three models is below $7.35 \mathrm{~kJ} / \mathrm{mol}$. It is observed that the activation energy $E_{\alpha}$ increases with the increase of mass loss fraction (up to 0.5 ) of the sample and thereafter decrease. The prediction of activation energy, therefore, opens up potential measure for life prediction of product and its fitment to use.

\section{ACKNOWLEDGEMENT}

The authors are grateful to the financial support given by Center for Leather, Rubber, and Plastics, Ministry of Industry, Indonesia.

\section{REFERENCES}

Damartzis, T., Vamvuka, D., Sfakiotakis, S., \& Zabaniotou, A. (2011). Thermal degradation studies and kinetic modeling of cardoon ( $\mathrm{C}$ ynara cardunculus) pyrolysis using thermogravimetric analysis (TGA). Bioresource Technology, 102(10), 62306238.

https://doi.org/10.1016/j.biortech.2011.02.060
Martins, M. A., Moreno, R. M. B., McMahan, C. M., Brichta, J. L., Goncalves, P. de S., \& Mattoso, L. H. C. (2008). Thermooxidative study of raw natural rubber from Brazilian IAC 300 series clones. Thermochimica Acta, 474(1-2), 62-66.

https://doi.org/10.1016/j.tca.2008.06.001

Nabil, H., Ismail, H., \& Azura, A. R. (2013). Comparison of thermo-oxidative ageing and thermal analysis of carbon black-filled NR / Virgin EPDM and NR / Recycled EPDM blends. Polymer Testing, 32(4), 631-639. https://doi.org/10.1016/j.polymertesting.2013. 03.019

Wang, J., \& Zhao, H. (2015). Thermogravimetric Analysis of Rubber Glove Pyrolysis by Different Iso-conversional Methods. Waste and Biomass Valorization, 527-533. https://doi.org/10.1007/s12649-015-9372-5

Xiang, K., Wang, X., Huang, G., Zheng, J., Huang, J., \& Li, G. (2014). Thermogravimetric studies of styrene - butadiene rubber ( SBR ) after accelerated thermal aging. Journal of Thermal Analysis and Calorimetry, 115, 247254. https://doi.org/10.1007/s10973-0133236-7

Yuniari, A., Sholeh, M., \& Indrajati, I. (2015). Pengaruh sistem vulkanisasi konvensional (CV) dan semi efisien (SEV) terhadap sifat aging dan termal vulkanisat campuran karet alam dan karet butil. Majalah Kulit, Karet, Dan Plastik, 31(2), 99-106. https://doi.org/10.20543/mkkp.v31i2.173

Zhao, Y., Yan, N., \& Feng, M. W. (2013). Thermal degradation characteristics of phenolformaldehyde resins derived from beetle infested pine barks. Thermochimica Acta, $555,46-52$.

Zheng, W., Jia, Z., Zhang, Z., Yang, W., Zhang, L., $\& \mathrm{Wu}$, S. (2016). Improvements of lanthanum complex on the thermal-oxidative stability of natural rubber. Journal of Materials Science, 51(19), 9043-9056. https://doi.org/10.1007/s10853-016-0157-4

Zheng, W., Liu, L., Zhao, X., He, J., Wang, A., Chan, T. W., \& Wu, S. (2015). Effects of lanthanum complex on the thermo-oxidative aging of natural rubber. Polymer Degradation and Stability, 120, 377-383. https://doi.org/10.1016/j.polymdegradstab.201 $\underline{5.07 .024}$ 
